Roberto Funes Abrahão ${ }^{1}$

Mauro José Andrade Tereso ${ }^{1}$

Sandra Francisca Bezerra Gemma ${ }^{2}$

\section{A Análise Ergonômica do Trabalho (AET) aplicada ao trabalho na agricultura: experiências e reflexões}

\author{
The Ergonomic Work Analysis (EWA) applied to agricultural \\ work: experiences and reflections
}

1 Universidade Estadual de Campinas, Faculdade de Engenharia Agrícola, Conselho de Planejamento e Gestão. Campinas, SP, Brasil.

${ }^{2}$ Universidade Estadual de Campinas, Faculdade de Ciências Aplicadas, Programa de Pós-graduação Interdisciplinar em Ciências Humanas e Sociais Aplicadas. Limeira, SP, Brasil.

Contato:

Mauro José Andrade Tereso

E-mail

mauro@feagri.unicamp.br

Este artigo não foi baseado em tese e não foi apresentado em reunião científica.

Os autores declaram não haver conflitos de interesses e que o trabalho não foi subvencionado.

\section{Resumo}

Objetivo: este trabalho resume a experiência do Grupo de Pesquisa em Ergonomia, Trabalho e Agricultura, do Programa de Pós-Graduação da Faculdade de Engenharia Agrícola da Universidade Estadual de Campinas (UNICAMP), sobre a análise do trabalho agrícola com a utilização da Análise Ergonômica do Trabalho (AET). Método: reflexão circunstanciada com base no referencial teórico-metodológico da AET. Resultados: apresentam-se reflexões sobre a utilização da AET em um contexto de pesquisa acadêmica, focado no estudo do trabalho na agricultura, por meio de estudos sobre o trabalho na fruticultura e horticultura orgânica, na colheita manual da cana-de-açúcar, na avicultura de corte, em unidades de beneficiamento de tomates e na colheita florestal. Conclusões: a AET mostrou-se apropriada como um meio de aproximação ao objeto da pesquisa e sua utilização auxiliou na lapidação das hipóteses iniciais e no detalhamento dos procedimentos metodológicos.

Palavras-chave: Análise Ergonômica do Trabalho; agricultura; pesquisa; trabalho agrícola.

\begin{abstract}
Objective: this paper summarizes the experience of the Research Group on Ergonomics, Work and Agriculture, within the graduate program of the College of Agricultural Engineering at Campinas State University, on the analysis of agricultural labor using the Ergonomic Work Analysis (EWA) method. Method: detailed reflection based on the theoretical and methodological EWA reference. Results: Reflections are shown on the EWA use in an academic research context focused on the study of agricultural work using studies on organic fruitculture and horticulture, sugar cane manual harvesting, in poultry production, in tomatoes packing houses and in forest harvesting. Conclusions: EWA was adequate as means of approaching the research object and its use helped to develop the initial hypotheses and set the methodological procedures details.
\end{abstract}

Keywords: Ergonomic Work Analysis; agriculture; research; agricultural work. 


\section{Introdução}

O Brasil é um dos maiores produtores de alimentos e possui uma das agriculturas mais produtivas do mundo. O agronegócio brasileiro foi responsável em 2008 por $33 \%$ do produto interno bruto, $42 \%$ das exportações e $37 \%$ do emprego, movimentando mais de 150 bilhões de dólares e empregando em torno de 17,7 milhões de pessoas (BRASIL, 2012). Do conjunto de trabalhadores engajados na produção agrícola, apenas $1 / 4$ possui carteira de trabalho assinada. São mais de 5 milhões de estabelecimentos agrícolas, sendo que em $84,4 \%$ deles se pratica a agricultura familiar, que ocupa menos de 1/4 da área cultivada no país e mais de 3/4 dos trabalhadores agrícolas (INSTITUTO BRASILEIRO DE GEOGRAFIA E ESTATÍSTICA, 2012).

As organizações rurais, assim como os demais setores da economia, vêm sendo premidas pela competição e pela busca da qualidade, levando-se à adoção de novas técnicas produtivas, com seu rol de novas tecnologias, que mudam o modo como o trabalho é tradicionalmente executado e organizado. Nessas condições, o trabalho agrícola vem sofrendo novas exigências: o aumento da cobrança por qualidade e produtividade e, em função da introdução de novas tecnologias, uma maior necessidade de qualificação e de desenvolvimento de novas habilidades. O fenômeno da globalização, que traz ao mundo do trabalho agrícola uma visibilidade inédita das condições de execução das tarefas, tem obrigado as organizações locais a se enquadrarem em padrões mínimos de higiene e de segurança do trabalho.

De acordo com a Organização Internacional do Trabalho, a agricultura é um dos três setores de atividade mais perigosos - os outros dois são a construção civil e a mineração -, sujeitando o trabalhador a um conjunto variado de fatores de risco de natureza física, química, mecânica e ergonômica (INTERNATIONAL LABOUR ORGANIZATION, 2009). A inadequação dos equipamentos de proteção individual utilizados na agricultura é um fator relevante na precarização das condições de trabalho (VEIGA et al., 2007; GONZAGA; ABRAHÃO; BRAUNBECK, 2005). Segundo Pinzke (1997), as estatísticas internacionais indicam que a agricultura é o segmento econômico com a mais alta prevalência de problemas osteomusculares. A movimentação manual de cargas, a flexão acentuada de tronco com alta frequência e por longos períodos e o trabalho repetitivo de membros superiores foram identificados por Fathallah (2010) como os fatores de risco prevalentes no trabalho agrícola e geradores dos distúrbios osteomusculares.

Diante desse quadro, propomos uma reflexão sobre o uso da Análise Ergonômica do Trabalho (AET) em um contexto de pesquisa acadêmica para a análise do trabalho na agricultura, com base no referencial teórico-metodológico da AET.

\section{O trabalho na agricultura e a Análise Ergonômica do Trabalho}

As mudanças no universo do trabalho agrícola aumentam o desafio da Ergonomia como disciplina contribuinte para o bem-estar do trabalhador e para a eficiência e a eficácia da produção. Da pequena produção familiar de subsistência até os modernos complexos agroindustriais, verifica-se um grande leque de condições tecnológicas e organizacionais no mundo do trabalho agrícola. A grande variabilidade das situações e das relações de trabalho - assalariado, familiar, arrendatário, meeiro, terceiro, parceiro ${ }^{3}$ - dificulta a elaboração de um diagnóstico generalizado das condições de trabalho na agricultura brasileira.

Apesar da grande variabilidade, o trabalho na agricultura tem certas características que o distingue dos demais setores, por obedecer a ritmos biológicos particulares, já que o processo produtivo agrícola se desenvolve, em algumas de suas fases, independentemente do trabalho humano. Via de regra, o trabalho acontece ao ar livre, sob condições ambientais incontroláveis e utiliza uma grande variabilidade de ferramentas, utensílios e técnicas. Além disso, a exigência física é, geralmente, elevada.

Na esfera da organização, o trabalho agrícola também exibe certas particularidades: escassez de treinamento; longas jornadas; trabalho espacialmente disperso; deslocamento excessivo; grande diversidade de atividades na jornada e ao longo do ciclo produtivo; estrutura organizacional linear, sem muitos níveis hierárquicos e de cunho paternalista; baixa remuneração; dificuldade de distinção entre ambientes familiar e de trabalho. Prevalecem nas organizações rurais os valores coletivistas, como a obediência, a segurança, o dever, a hierarquia, e as relações personalizadas, que moldam as relações de trabalho no campo (GUIMARÃES; BRISOLA; ALVES, 2005).

Wisner (1987) afirma que na agricultura encontram-se, frequentemente, todos os tipos de trabalho humano: trabalho primário (sobre a terra e seus produtos); trabalho secundário (como a fabricação e reparo de ferramentas); trabalho terciário (como a gestão e contabilidade). Em contraposição ao trabalho taylorista, no qual o operador tem uma tarefa única e bem definida pela organização do trabalho, o trabalho na agricultura é complexo, comportando múltiplas atividades e tarefas (MONTEDO;

\footnotetext{
3 Na produção familiar, trabalha-se diretamente a terra com mão de obra predominantemente familiar; o arrendatário trabalha a terra mediante pagamento de aluguel em dinheiro; os parceiros pagam pelo uso da terra com uma porcentagem do produto colhido; os meeiros e os terceiros são também parceiros que dividem os custos de produção com o proprietário e pagam pelo uso da terra, respectivamente, com metade e $1 / 3$ da produção (KAGEYAMA; BERGAMASCO; OLIVEIRA, 2013).
} 
SNELWAR, 2008; GEMMA; TERESO; ABRAHÃO, 2010). O operador é levado a organizar seu tempo e a ordenar suas diversas tarefas em função de fatos novos que se produzem sucessivamente. Para Cerf e Sagory (2007), o ofício do agricultor exige competências múltiplas para gerir uma grande diversidade de processos biológicos e físicos com ritmos temporais diversos. Os agricultores são os projetistas e os executores de seu trabalho, realizando arbitragens que envolvem muitas lógicas (econômica, patrimonial, técnica, organizacional e ecológica). Há uma grande interdependência entre as tarefas e uma incerteza constante que dificultam a tomada de decisões.

No entanto, nos modernos complexos agroindustriais, a natureza do trabalho executado pelos operários agrícolas guarda mais semelhança com o trabalho industrial: com jornadas regulares, tarefas estruturadas e alguma especialização.

A produção acadêmica brasileira voltada à temática da agricultura é muito consistente e mundialmente reconhecida. A maior parte das contribuições situa-se na esfera da produtividade, do desenvolvimento tecnológico e nas abordagens socioeconômicas. Os estudos acerca das condições de trabalho rural são ainda em pequeno número e abordam, predominantemente, questões ligadas à higiene e à segurança do trabalho sob a perspectiva tradicional da corrente Human Factors. Somente uma parcela reduzida desses estudos utilizou a AET como instrumento de análise (GUIMARÃES, 2007).

A AET foi concebida como prática profissional e sua aplicação tem início a partir de uma demanda real, externa, formulada por um ou mais atores sociais envolvidos na situação de trabalho. A instrução dessa demanda, feita pelo ergonomista em conjunto com os demais atores, presta-se ao necessário recorte/delimitação a ser feita na situação de trabalho. No contexto de uma pesquisa acadêmica, a própria formulação do projeto já traz em seu bojo a demanda (e o recorte). De qualquer forma, essa "demanda científica" é também instruída em conjunto - pesquisadores e atores sociais das situações de trabalho. O papel da análise da demanda em um contexto de pesquisa seria o de confirmar com os diferentes atores sociais da situação de trabalho a pertinência e a relevância do projeto proposto.

Com relação à etapa relativa à análise do processo técnico e da tarefa, pode-se afirmar que, em uma AET profissional, a análise é feita de forma exaustiva, o mais abrangente possível. Já no contexto de um projeto de pesquisa, essa análise é mais focada, direcionada aos objetivos delineados pelo projeto.

De qualquer forma, a AET utilizada no contexto de uma pesquisa científica retém suas principais características: a observação e a análise do trabalho executado em condições reais (não simuladas), revelando a atividade concreta de trabalho e a interlocução com os diferentes atores do trabalho.
A AET foi concebida em um contexto - sociotécnico, no qual o posto de trabalho é um elemento presente e constante nas organizações, o que é característico das organizações industriais. Via de regra, na agricultura não se identificam postos de trabalho; o foco da análise é voltado mais ao conjunto de tarefas e de operações que compõem os sistemas de trabalho da agricultura.

\section{Experiências de pesquisa}

Os trabalhos de pesquisa citados a seguir, produzidos pelo Grupo de Pesquisa em Ergonomia, Trabalho e Agricultura (GETA), do Programa de Pós-Graduação da Faculdade de Engenharia Agrícola da Universidade Estadual de Campinas (FEAGRI/UNICAMP), utilizaram elementos da AET (GUÉRIN et al., 2001) fundamentalmente como um meio de aproximação ao objeto da pesquisa. Sua utilização auxiliou na lapidação das hipóteses iniciais e no detalhamento dos procedimentos metodológicos dessas pesquisas. Outros procedimentos metodológicos de disciplinas afins foram utilizados em função das especificidades de cada projeto. A seguir, para além da descrição sintética de cada pesquisa, buscou-se explicitar como a AET contribuiu para o seu desenvolvimento.

- O trabalho no cultivo orgânico de frutas: uma abordagem ergonômica (GEMMA; ABRAHÃO; SZNELWAR, 2004). Essa pesquisa teve por objetivo principal a compreensão das dificuldades encontradas na execução do trabalho na produção orgânica de frutas. Foi realizado um estudo de caso em um sítio de cultivo orgânico de frutas com aplicação do método da AET, a qual desvelou a organização do trabalho e as tarefas vinculadas aos diferentes sistemas de trabalho (preparação de solo, plantio e transplantio de mudas, tratos culturais, colheita e pós-colheita), permitindo hierarquizar as dificuldades encontradas pelos trabalhadores em sua execução. Esse mergulho no trabalho real orientou a pesquisa para a atividade de ensacamento de frutas no pé, cujos determinantes eram de natureza física (como o alcance das frutas nos galhos mais altos, trabalho em escada com uso de ganchos e movimentos repetitivos) e cognitiva (as escolhas necessárias para executar o raleio e as estratégias utilizadas para dar conta das tarefas e dos incidentes). A observação da atividade dos agricultores revelou as estratégias para fazer frente às dificuldades oriundas da falta de tecnologia apropriada ao cultivo orgânico, tais como o uso de ganchos adaptados pelos próprios trabalhadores para aproximar os galhos das árvores. Foi possível interpretar o trabalho do raleio de frutas, que antecede o ensacamento, na forma de um fluxograma das decisões que o agricultor tomava no decorrer da atividade, a qual comportava várias subtarefas e ações específicas que revelam uma complexidade não reconhecida, inicialmente, nem pelos próprios agricultores. Também foi possível conhecer, por meio 
da análise do trabalho real, as estratégias adotadas para definir, espacialmente, as regiões e as direções adotadas para realizar o ensacamento dos frutos na árvore e para enfrentar a diversidade de incidentes e as devidas recuperações. Tarefas manuais frequentes no cultivo orgânico, como o ensacamento de frutas, executadas sob pressão temporal, podem colocar em risco a saúde dos agricultores por demandar esforço físico considerável, posturas desconfortáveis e movimentos repetitivos.

- O uso de luvas de proteção no corte manual da cana-de-açúcar (GONZAGA; ABRAHÃO; BRAUNBECK, 2005). Problemas relacionados ao uso de equipamentos de proteção individual, especialmente as luvas de proteção utilizadas no corte manual da cana-deaçúcar, motivaram essa pesquisa, tornada possível por um acordo tripartite entre o Ministério do Trabalho e Emprego, o Sindicato dos Trabalhadores Rurais e o Sindicato Patronal de Produção de Cana do Estado de São Paulo. O objetivo principal foi avaliar, a partir de uma perspectiva ergonômica, o impacto do uso de diferentes modelos de luvas de proteção durante a colheita manual, levantando-se questões sobre segurança, efetividade e conforto. A metodologia utilizada incluiu o uso de entrevistas semiestruturadas, questionários e observações de campo. A AET foi fundamental para conhecer as estratégias adotadas pelos trabalhadores no corte manual da cana-de-açúcar, especialmente aquelas utilizadas para melhorar a aderência entre a luva e o facão, tais como molhar as luvas durante a execução do trabalho e emborrachar o cabo com retalhos de câmaras de pneu de bicicleta. Em consequência, procurou-se testar uma hipótese relativa à perda de aderência da luva com o cabo do facão durante o corte manual, determinando-se, experimentalmente, o coeficiente de atrito entre esses elementos em diferentes momentos da vida útil da luva. A pesquisa qualitativa apontou a luva de proteção de raspa de couro e naylon como a preferida pelos trabalhadores por se ajustar bem às mãos, não prejudicar os movimentos nem ocasionar danos. Na seleção das luvas, o atrito não foi prioritário para os trabalhadores, pois a estratégia de emborrachamento minimiza esse problema. Os resultados obtidos nas avaliações das luvas em condição de laboratório corroboraram as estratégias utilizadas pelos trabalhadores, identificadas por meio da AET.

- Organização do trabalho e recursos tecnológicos na produção avícola: uma abordagem ergonômica (DINTEN; ABRAHÃO; OLIVEIRA, 2006). Esse trabalho, realizado junto a unidades avícolas de uma cooperativa do interior do Estado de São Paulo, teve como objetivo verificar as relações entre as formas de organização do trabalho, a tecnologia empregada na produção e os impactos sobre o trabalho do ponto de vista ergonômico. O método da AET permitiu identificar os principais fatores relacionados às dificuldades na execução das tarefas. O trabalho em equipe e a colaboração entre os funcionários ajudaram a minimizar esforços e a alcançar melhores resultados. Observou-se que, se, por um lado, o grau de tecnologia adotado permitiu o emprego de um número menor de trabalhadores e tornou o manejo mais fácil e preciso, por outro, criou subtarefas e fez com que o bom funcionamento dos equipamentos dependesse muito da vigilância dos funcionários. Com a diminiução dos constrangimentos físicos, como o menor transporte de carga, criaram-se outros constrangimentos de ordem cognitiva, como a intensificação da vigilância da tecnologia. A AET desvelou que, do ponto de vista do esforço físico, as tarefas de manejo de $\operatorname{cortinas}^{4}$ e de retirada de aves mortas foram as mais difíceis. A retirada da cama e a exposição aos seus odores provocavam mal-estar nos trabalhadores. As tarefas relacionadas à retirada de aves mortas e à refugagem - sacrifício das aves mais fracas - foram consideradas pelos trabalhadores como extremamente constrangedoras do ponto de vista emocional. As propriedades total ou parcialmente familiares obtiveram melhores resultados de produção do que as patronais. Aventou-se a hipótese de que a maior autonomia dos trabalhadores familiares e o uso de tecnologia consolidada foram responsáveis por essa diferença.

- Segurança do trabalho em unidades de beneficiamento de produtos agrícolas (ABRAHÃO et al., 2009); Análise ergonômica do trabalho em unidades de beneficiamento de produtos agrícolas: exigências laborais dos postos de seleção (BRAGA; ABRAHÃO; TERESO, 2009); Análise ergonômica do trabalho em unidades de beneficiamento de tomates de mesa: movimentação manual de cargas (RIBEIRO; TERESO; ABRAHÃO, 2009). Essas pesquisas tiveram como objeto o trabalho em unidades de beneficiamento de tomates, focando, respectivamente, os aspectos de segurança laboral e as tarefas de seleção de produtos e de movimentação manual de caixas. A AET foi utilizada nesses trabalhos como aproximação ao objeto, na construção das hipóteses e na definição das metodologias específicas adotadas para atingir os objetivos. No primeiro trabalho (ABRAHÃO et al., 2009), foram identificados os fatores de risco desses ambientes, analisados sob a ótica das normas vigentes, e foi proposto um conjunto de equipamentos de proteção individual, além da construção de uma lista de verificação para o diagnóstico das condições de trabalho em unidades em operação ou em projeto. No segundo trabalho (BRAGA; ABRAHÃO; TERESO, 2009), a AET trouxe à luz as dificuldades cognitivas relativas à tarefa de seleção nas unidades

\footnotetext{
4 Dispositivo utilizado nos galpões de produção avícola para controlar luminosidade e ventilação.
} 
de beneficiamento, explicitando a heterogeneidade em seus postos de trabalho. Foi escolhida a tarefa de seleção dos produtos sob o prisma das exigências mental, visual e física, utilizando o método NASA $\mathrm{TLX}^{5}$ e um questionário de avaliação visual. As análises revelaram a ocorrência de dores na nuca, na cabeça, nos olhos, nas pernas e nos pés. Foram identificadas dificuldades relacionadas ao volume de produção, ao ritmo de trabalho, à precária distribuição das tarefas, ao projeto e ao layout dos galpões, às características ambientais e à tecnologia adotada nas unidades de beneficiamento. A exigência física foi considerada elevada em todos os postos com movimentação de caixas nas seis unidades. A exigência mental foi elevada nos postos de seleção, e a exigência visual, nas unidades com baixos níveis de iluminância. As observações sistemáticas da atividade revelaram que os operadores realizavam muitas operações ao mesmo tempo (observavam o enchimento das caixas; movimentavam-nas para pesagem; colocavam-nas nos paletes; tudo ocorrendo simultaneamente às operações de seleção), o que também influenciou os valores de exigência mental elevados. A AET, no terceiro trabalho (RIBEIRO; TERESO; ABRAHÃO, 2009), desvelou a importância das exigências físicas no transporte de caixas nas unidades de beneficiamento, em especial a movimentação manual. Foram identificados os postos de trabalho em que essa tarefa revelou-se mais intensa. A análise do trabalho real permitiu caracterizar as atividades e orientou na escolha da metodologia mais adequada para avaliar a exigência física. A movimentação manual de caixas foi estudada utilizando-se o método de análise da equação do National Institute for Occupational Safety and Health $(\mathrm{NIOSH})^{6}$, que avalia o risco do surgimento de distúrbios osteomusculares, relacionando o limite de peso recomendado com o peso efetivamente manipulado. Em todos os casos estudados, o peso real movimentado superou o limite recomendado pelo método. O posto de descarregamento de caminhões foi o que apresentou a maior discrepância entre os valores manipulados e recomendados pelo método, corroborando as verbalizações dos trabalhadores, os quais classificaram o posto como o de maior desgaste físico. Os trabalhadores apontaram desconforto elevado na coluna lombar, ombros, pescoço, braços e antebraços. Dos seis parâmetros que compõem a equação do NIOSH, os que mais impactaram os resultados foram o período de exposição, a frequência de levantamentos/abaixamentos e as alturas dos deslocamentos. A movimentação manual de cargas apresentou-se muito intensa nos diversos postos que compõem o fluxo de produção. Essa intensidade foi decorrente dos fatores determinantes das tarefas, que estão diretamente ligados ao volume de produção, ao tipo de tecnologia empregada e ao número de trabalhadores disponível para executar as tarefas. O processo de produção emprega alta tecnologia no que diz respeito aos equipamentos de beneficiamento, compostos por dispositivos com tecnologia digital (computadores, câmeras de vídeo e sensores de temperatura), sendo muitos deles importados. No entanto, nas etapas do processo em que predomina o trabalho humano, tecnologias para o auxílio da movimentação de carga foram identificadas somente no posto de carregamento de caminhões e em algumas unidades de beneficiamento. Ainda assim, o dispositivo de auxílio mais comum foi a paleteira mecânica, que exige grande esforço físico para sua manipulação. Concluiu-se que todos os postos de trabalho com movimentação manual de cargas precisam ser modificados, já que os riscos são moderados ou elevados em todos os casos. Os organizadores do trabalho devem avaliar a possibilidade de redução do peso das caixas - ou mesmo redefinir outros determinantes das tarefas que levem a uma modificação da frequência de levantamentos e abaixamentos de caixas -, a diminuição do período de exposição às tarefas e a necessidade de um maior número de operadores.

- Ergonomia e complexidade: o trabalho do gestor na agricultura orgânica (GEMMA; TERESO; ABRAHÃO, 2010). Investigou-se, por meio da AET e da Teoria da Complexidade (MORIN, 2003), as características do trabalho na agricultura orgânica, particularmente o trabalho dos gestores, focando os aspectos da organização do trabalho e da tecnologia utilizada. Buscou-se ampliar a compreensão das atividades desenvolvidas, suas dificuldades e as estratégias de superação. Observou-se que o gestor da produção orgânica é, geralmente, administrador e executor do trabalho. Ele assume as funções administrativas de planejamento, organização, direção e controle de todas as áreas: produção, manutenção, finanças, recursos humanos e comércio, bem como a responsabilidade pelas questões ligadas à certificação, ao reflorestamento e à conservação dos recursos naturais na unidade de produção. Por meio da AET, desvelou-se que o gestor necessita pensar a unidade de produção de forma integrada e sistêmica, entendendo-a e tratando-a como um ser vivo, observando e identificando os elementos que o auxiliem na tomada de decisões para enfrentar múltiplas dificuldades, em um ambiente em que não se dispõe de tecnologia apropriada, com poucos recursos financeiros e sem assessoria técnica. As dificuldades relatadas pelos gestores são de natureza bastante variada, desde aquelas relacionadas às exigências predominantemente físicas, cognitivas e afetivas do trabalho até aquelas relacionadas mais diretamente à falta de

\footnotetext{
5 Método de natureza subjetiva utilizado na avaliação dos diferentes elementos constituintes da carga de trabalho.

6 Método utilizado para avaliação do grau de risco associado às tarefas de levantamento e de abaixamento manual de cargas.
} 
recursos tecnológicos, organizacionais, materiais, financeiros e humanos. Concluiu-se que o trabalho na agricultura orgânica é complexo, pois incorpora os preceitos ecológicos, econômicos e sociais de sustentabilidade, que podem ser contraditórios entre si e que geram incertezas para o trabalho do gestor. Essa complexidade do trabalho se relaciona com a necessidade de integrar múltiplas dimensões, demandando do gestor o desenvolvimento e a integração de variados saberes a fim de criar uma organização dinâmica do trabalho e que precisa ser frequentemente reconstituída devido ao grande número de interações e de relações complementares e antagonistas entre ordem e desordem.

- Elementos da carga de trabalho na horticultura orgânica (ABRAHÃO; RIBEIRO; TERESO, 2012). Essa pesquisa buscou caracterizar a carga física de trabalho da horticultura orgânica ao determinar a frequência de exposição dos trabalhadores às categorias relevantes da atividade. Por meio de um estudo-piloto, a AET permitiu conhecer os diferentes sistemas de trabalho e orientou na identificação das metodologias mais adequadas para avaliar as exigências físicas na horticultura orgânica (utilizando parâmetros fisiológicos, biomecânicos e psicofísicos). Fez-se uma adaptação do método PATH$^{7}$ (Posture, Activities, Tools and Handling), desenvolvido por Buchholz et al. (1996), para sua utilização na análise do trabalho agrícola, substituindo as planilhas de observação pela filmagem integral da jornada de trabalho, com posterior análise dos frames a cada 5 segundos para registrar a postura corporal adotada, a ação operacional e as ferramentas utilizadas. A abordagem incluiu uma avaliação do esforço físico, exigido para a execução das tarefas dos diversos sistemas de trabalho, a partir de: amostragem sistemática das situações laborais e da monitoração sincronizada do parâmetro fisiológico frequência cardíaca; caracterização do repertório postural adotado pelos trabalhadores pela adaptação do método OWAS ${ }^{8}$ (IIDA, 2005); identificação das áreas do corpo dos trabalhadores que apresentam desconforto pela aplicação do diagrama das áreas dolorosas ${ }^{9}$; avaliação do esforço percebido por meio da aplicação da escala RPE ${ }^{10}$. Buscou-se correlacionar os resultados das avaliações particulares e interpretá-los à luz da observação da atividade dos trabalhadores. Os resultados sugeriram que o método adotado mostrou-se eficiente para caracterizar a carga de trabalho da horticultura orgânica. Para a maioria dos trabalhadores monitorados nessa pesquisa, do ponto de vista cardiovascular, observou-se que o trabalho foi classificado como leve e moderado.
Nas poucas situações em que esse indicador mostrou-se mais intenso, uma análise detalhada apontou que as características individuais do operador tiveram maior influência nesse resultado. Percebeu-se que determinadas ações operacionais ligadas à movimentação manual de cargas exigiram, momentaneamente, um esforço maior do sistema cardiovascular. O mesmo ocorreu nas poucas situações em que se exigiu do trabalhador um aumento na velocidade de execução das tarefas. Três combinações posturais foram predominantes ao longo da jornada de trabalho: tronco neutro, braços para baixo e pernas estendidas; flexão moderada do tronco (menor que $45^{\circ}$ ), braços para baixo e pernas flexionadas; flexão severa do tronco (maior que $45^{\circ}$ ), braços para baixo e pernas flexionadas. Essas três combinações foram adotadas em 93,3\% do tempo na jornada e, em seu conjunto, configuram um trabalho de alta exigência biomecânica-postural. O estudo das combinações posturais adotadas pelos trabalhadores no cumprimento das tarefas mostrou que a adoção de determinado repertório postural por um trabalhador é fruto de uma interação complexa entre elementos específicos da tarefa e de suas estratégias pessoais. As combinações posturais adotadas atenuaram situações de desconforto, permitiram a recuperação de grupos musculares e regularam a atividade, buscando ganhos de desempenho. No geral, as tarefas que geraram combinações posturais mais severas foram adubação e cobertura, fixação de mudas, capina e colheita. Os depoimentos colhidos a partir do diagrama de áreas dolorosas, de maneira geral, corroboraram esses resultados. As exigências posturais foram mais significativas que as cardiovasculares para as tarefas estudadas. No que diz respeito à percepção do esforço despendido na horticultura orgânica, a adubação, a cobertura, o plantio/semeadura, o transplantio de mudas, a capina, a colheita e o transporte foram consideradas tarefas em que o esforço percebido foi de intenso a extremamente intenso. No entanto, todas as tarefas de pós-colheita foram consideradas leves ou pouco intensas. O desenvolvimento tecnológico para assistir ao trabalho humano na horticultura deveria ser priorizado para as tarefas ligadas ao plantio, aos tratos culturais e à colheita, tanto para minimizar os efeitos deletérios da carga de trabalho como para aumentar a sua produtividade.

- Avaliação ergonômica da operação de máquinas de colheita florestal (ABRAHÃO; ALMEIDA; TERESO, 2012). Nesse trabalho, a AET permitiu explicitar as dificuldades do trabalho dos operadores de máquinas de colheita florestal, ressaltando o papel das

\footnotetext{
7 Método de análise desenvolvido para a construção civil que registra frequência de ocorrência de determinadas categorias da atividade laboral.

8 Método de registro e de diagnóstico de posturas corporais.

9 Método de registro das áreas corporais dolorosas e do grau de desconforto associado.

${ }^{10}$ Método psicofísico de avaliação do esforço percebido na execução de tarefas.
} 
vibrações a que estão submetidos esses trabalhadores e orientando a escolha das metodologias utilizadas. Foram entrevistados os gestores e os operadores das diferentes máquinas florestais. $\mathrm{O}$ trabalho dos operadores foi amplamente descrito por meio das observações e das filmagens da atividade. A pesquisa foi realizada em áreas de colheita de eucalipto de uma empresa de celulose e de papel, com o objetivo de quantificar os níveis de vibração aleatória a que estão expostos os operadores de três diferentes tipos de máquina de colheita de madeira (Feller-Buncher, Skidder e Garra Traçadora) durante a jornada de trabalho e de analisá-los à luz das recomendações das normas ISO 2631-1 e Diretiva 2002/44 da Comunidade Europeia (ALMEIDA, 2011). Pôde-se constatar que a atividade laboral do operador de máquina florestal é uma tarefa complexa, que demanda muito tempo em uma mesma postura (sentada), com o agravante da vibração recebida durante praticamente $75 \%$ da jornada diária. As tarefas apresentaram alta exigência cognitiva e motora, com movimentos de mãos e de punhos simultâneos, porém assimétricos; curtos e leves, porém com alto índice de repetitividade. Maior número de pausas e de exercícios que compensem os esforços da musculatura mais solicitada durante a jornada de trabalho tem sido amplamente estudado, e seus benefícios, comprovados. Nota-se que, apesar de toda tecnologia envolvida em cada máquina avaliada, os achados relativos à exposição ocupacional dos operadores às vibrações mecânicas se mostraram em patamares que suscitam ações mais eficazes, podendo-se considerar, inclusive, a diminuição da jornada de trabalho. $\mathrm{O}$ fato de não se obter informações mais precisas, com os sindicatos de trabalhadores rurais, sobre esse operador de máquinas de colheita florestal pode mascarar a sua realidade com relação a acidentes ou a doenças ocupacionais. Obteve-se uma pequena amostra com essa pesquisa, com saldo bastante positivo, mas o número de operadores ativos no país é uma incógnita, e as condições de trabalho a que estão expostos são igualmente desconhecidas. Apesar de toda tecnologia empregada pelos fabricantes de máquinas de colheita florestal, os níveis de exposição às vibrações ainda estão acima dos parâmetros recomendados pelas normas. A problemática da vibração foi compreendida para além de seus aspectos biomecânicos, estabelecendo-se relação com a própria atividade laboral.

- Trabalho e inovação tecnológica na agricultura orgânica (TERESO et al., 2012). Essa pesquisa teve por objetivo mapear a inovação tecnológica que, simultaneamente, minimizasse a carga laboral e as dificuldades na execução das tarefas e que aumentasse a produtividade do trabalho em propriedades de produção orgânica de hortaliças representativas do Estado de São Paulo. Para compreender a inovação na agricultura orgânica, adotou-se a tipologia proposta pela OECD (ORGANISATION FOR ECONOMIC CO-OPERATION AND DEVELOPMENT, 2005): a inovação de produto corresponde à introdução de novos ou significativamente melhorados produtos ou serviços, incluindo as alterações significativas nas suas especificações técnicas ou outras características funcionais (na agricultura orgânica seriam as ferramentas, máquinas, equipamentos e instrumentos adotados); a inovação de processo corresponde à adoção de novos ou significativamente melhorados processos de produção ou de logística de bens ou serviços (na agricultura orgânica corresponderiam aos processos adaptativos dos cultivares, às técnicas utilizadas para lidar com os recursos naturais da produção e da propriedade, além das estratégias utilizadas para controlar agentes biológicos que disputam com a produção); a inovação organizacional corresponde à implementação de novos métodos organizacionais, seja nas práticas de negócios da empresa, na organização do local de trabalho ou nas relações externas (seriam exemplos a adoção de novas práticas de trabalho em equipe, de gestão e de coordenação, a associação com terceiros e o trabalho cooperativo); a inovação de marketing corresponde à adoção de novos métodos de marketing, envolvendo melhorias significativas no design do produto ou da embalagem, no preço, na distribuição e na promoção (na agricultura orgânica poderiam ser as estratégias de comercialização na conquista de novos nichos de mercado e as associações com outros produtores para fortalecer a oferta aos clientes). A AET permitiu definir a metodologia adotada nessa pesquisa, em especial a construção do questionário utilizado para orientar as entrevistas aos gestores das propriedades com o intuito de construir o quadro de inovações tecnológicas característico da horticultura orgânica no Estado de São Paulo. Posteriormente, foi utilizada para compreender o trabalho dos gestores no que diz respeito às escolhas e às estratégias adotadas na adoção de novas tecnologias em suas unidades de produção, bem como as principais dificuldades tecnológicas encontradas para dar conta de suas demandas laborais. Foram entrevistados 33 gestores, que revelaram variada experiência com a agricultura orgânica, desde aqueles que recentemente se certificaram até aqueles que possuem mais de 20 anos nesse modo de produção. A maioria das unidades de produção pesquisadas é familiar, com área total inferior a 20 hectares, ainda que algumas unidades de produção contratem trabalhadores assalariados. Todas possuem uma área de preservação ambiental e se caracterizam pela diversidade de produção. A maioria dos trabalhadores executa todas as tarefas na produção orgânica. As exceções se restringem às poucas tarefas que exigem muita força - feita somente por homens, como a colheita de raízes - ou à operação de máquinas e de equipamentos como trator e pulverizadores. Algumas inovações em marketing foram identificadas, tais como a 
entrega de cestas de produtos a domicílio a partir de solicitação feita pela internet e o desenvolvimento de marcas e de embalagens próprias para os produtos hortícolas, obedecendo aos princípios da rastreabilidade. Todos os produtores pesquisados inovaram em processos, especialmente no que se refere às adaptações agronômicas para introdução de novos cultivares. Cada situação revelou-se única, em função das características próprias da unidade de produção - microclima, solo, topografia e orientação do terreno, disponibilidade e qualidade da água. A maioria dos produtores também procurou desenvolver máquinas e ferramentas voltadas ao aumento da produtividade do trabalho. Destacam-se as adaptações voltadas à movimentação manual de cargas - carrinhos de mão para transporte de caixas e produtos colhidos - e aquelas dirigidas aos tratos culturais, tais como enxadas adaptadas ao cultivo em canteiros. A maior parte dos equipamentos e das ferramentas desenvolvidos pelos produtores na forma de tentativa e erro revelou-se pouco eficiente e logo foi abandonada pelos produtores. Isso demonstra a nítida demanda por desenvolvimento tecnológico para esse setor produtivo. Agricultores orgânicos dispõem de pouca oferta de tecnologia na forma de produtos (máquinas, equipamentos e ferramentas) desenvolvida especificamente para suas demandas. As principais inovações que permitiram vantagens competitivas ou que levaram a uma maior produtividade do trabalho ocorreram sob a forma de processos, organização e marketing.

O Quadro 1 apresenta a síntese das experiências relatadas.

Quadro 1 Síntese das pesquisas empregando Análise Ergonômica do Trabalho (AET) realizadas pelo GETA*

\begin{tabular}{|c|c|c|}
\hline Área & Enfoque & Síntese e contribuições \\
\hline \multirow{4}{*}{$\begin{array}{l}\text { Agricultura } \\
\text { orgânica }\end{array}$} & $\begin{array}{l}\text { Análise do trabalho na } \\
\text { fruticultura }\end{array}$ & $\begin{array}{l}\text { Hierarquizou as dificuldades encontradas na execução das tarefas, especialmente no } \\
\text { ensacamento de frutas. Os determinantes foram de natureza física (alcance das frutas } \\
\text { nos galhos mais altos, trabalho em escada com uso de ganchos adaptados e movimen- } \\
\text { tos repetitivos) e cognitiva (o conhecimento e as escolhas necessárias para executar o } \\
\text { raleio e as estratégias utilizadas para dar conta das tarefas e dos incidentes). }\end{array}$ \\
\hline & $\begin{array}{l}\text { Análise do trabalho na } \\
\text { horticultura }\end{array}$ & $\begin{array}{l}\text { Adaptou-se o método PATH para sua utilização na análise do trabalho agrícola, } \\
\text { substituindo as planilhas de observação pela filmagem integral da jornada de trab- } \\
\text { alho. Avaliou-se a carga física de trabalho nas dimensões fisiológica, biomecânica e } \\
\text { psicofísica. Apesar de a avaliação fisiológica apontar para um trabalho moderado, as } \\
\text { avaliações biomecânicas e psicofísicas revelaram que a carga de trabalho na horticul- } \\
\text { tura orgânica é pesada. }\end{array}$ \\
\hline & $\begin{array}{l}\text { Análise do trabalho na } \\
\text { gestão da produção }\end{array}$ & $\begin{array}{l}\text { O gestor necessita pensar a unidade de produção de forma integrada e sistêmica, } \\
\text { entendendo-a e tratando-a como um ser vivo, observando e identificando os elemen- } \\
\text { tos que o auxiliem na tomada de decisões para enfrentar múltiplas dificuldades, em } \\
\text { um ambiente em que não se dispõe de tecnologia apropriada, com poucos recursos } \\
\text { financeiros e sem assessoria técnica. }\end{array}$ \\
\hline & Inovação tecnológica & $\begin{array}{l}\text { Agricultores orgânicos dispõem de pouca oferta de tecnologia na forma de produtos } \\
\text { (máquinas, equipamentos e ferramentas) desenvolvida especificamente para suas } \\
\text { demandas. As principais inovações que permitiram vantagens competitivas ou que } \\
\text { levaram a uma maior produtividade do trabalho ocorreram sob a forma de processos, } \\
\text { organização e marketing. }\end{array}$ \\
\hline Florestal & $\begin{array}{l}\text { Análise da atividade na } \\
\text { colheita de eucalipto }\end{array}$ & $\begin{array}{l}\text { Explicitou as dificuldades do trabalho dos operadores de máquinas de colheita flo- } \\
\text { restal, ressaltando o papel das vibrações a que estão submetidos esses trabalhadores } \\
\text { e orientando a escolha das metodologias utilizadas. }\end{array}$ \\
\hline $\begin{array}{l}\text { Unidades de } \\
\text { beneficiamento }\end{array}$ & $\begin{array}{l}\text { Segurança, fadiga e movi- } \\
\text { mentação de carga }\end{array}$ & $\begin{array}{l}\text { Segurança laboral pelo mapeamento de riscos. Foram identificados os postos de } \\
\text { trabalho em que a fadiga foi mais intensa, relacionando-a ao volume de produção, } \\
\text { ao ritmo e à organização do trabalho, ao layout e às características ambientais dos } \\
\text { galpões. Foram estudados os postos de trabalho em que a movimentação manual de } \\
\text { carga foi mais intensa. Os riscos identificados demonstram a necessidade de redução } \\
\text { do peso das caixas movimentadas, a diminuição do período de exposição às tarefas de } \\
\text { movimentação e a necessidade de tecnologias de auxílio à movimentação de carga. }\end{array}$ \\
\hline Avicultura & $\begin{array}{l}\text { Organização, tecnologia } \\
\text { e trabalho na produção } \\
\text { patronal e familiar }\end{array}$ & $\begin{array}{l}\text { Desvelou a intensificação do trabalho com o uso de novas tecnologias e os constrangi- } \\
\text { mentos cognitivos a que estão submetidos os trabalhadores nessa atividade. Mostrou } \\
\text { como o trabalho mais intenso nas propriedades familiares levou a uma maior produ- } \\
\text { tividade na produção avícola. }\end{array}$ \\
\hline $\begin{array}{l}\text { Cultivo de } \\
\text { cana-de-açúcar }\end{array}$ & $\begin{array}{l}\text { Análise da atividade na } \\
\text { colheita da cana-de açúcar }\end{array}$ & $\begin{array}{l}\text { Avaliação qualitativa das luvas de proteção pelos trabalhadores. Determinação do co- } \\
\text { eficiente de atrito entre a luva - em diferentes condições e tempo de uso - e o facão. }\end{array}$ \\
\hline
\end{tabular}




\section{Considerações finais}

Nas pesquisas acadêmicas sobre o trabalho na agricultura, a AET foi de grande valia na aproximação aos objetos de estudo, no aprimoramento das hipóteses e na definição dos procedimentos metodológicos adotados, os quais também envolveram metodologias de áreas afins. $\mathrm{O}$ uso conjunto da AET com as demais abordagens metodológicas específicas - em função dos objetivos perseguidos - revelou-se fecundo para compreender e para analisar o trabalho na agricultura.

O GETA realizou, durante e ao término de cada pesquisa, respectivamente, validações e devolutivas para os diferentes atores envolvidos. A essa atividade credita-se enorme importância, na medida em que possibilita a reconstrução das situações laborais contexto, dificuldades, problemas e estratégias vividas no trabalho - por esses atores, a partir da perspectiva da ergonomia da atividade, constituindo-se no primeiro e importante passo para as transformações das situações de trabalho.

De uma forma mais geral, os resultados dessas pesquisas, para além das publicações científicas, foram divulgados em revistas técnicas, jornais de circulação ampla, encontros com associações de classe, entrevistas em redes de rádio e televisão, o que também constituiu uma forma de dar maior visibilidade para o trabalho agrícola, potencializando as perspectivas de transformação, tanto no nível das propriedades agrícolas como na formulação de políticas públicas.

\section{Contribuições de autoria}

Todos os autores contribuíram igualmente na elaboração do trabalho.

\section{Referências}

ABRAHÃO, R. F. et al. Segurança do Trabalho em unidades de beneficiamento de produtos agrícolas. São Carlos: Embrapa, 2009. 4 p. (Comunicado Técnico, 102).

ABRAHÃO, R. F.; ALMEIDA, S. F.; TERESO, M. J. A. Ergonomic evaluation of logging machine operation. In: INTERNATIONAL CONFERENCE OF AGRICULTURAL ENGINEERING, 2012. Valencia, Espanha. Proceedings... Valencia: CIGR, 2012. p. 1-5. CD ROM.

ABRAHÃO, R. F.; RIBEIRO, I. A. V.; TERESO, M. J. A. Workload composition of the organic horticulture. Work, Reading, v. 41, p. 5355-5360, 2012. Suplemento 1. PMid:22317549.

ALMEIDA, S. F. Aspectos ergonômicos da tarefa do operador de máquina de colheita florestal. 2011. 133 f. Dissertação (Mestrado em Engenharia Agrícola)Faculdade de Engenharia Agrícola, Universidade Estadual de Campinas, Campinas, 2011.

BRAGA, C. O.; ABRAHAO, R. F.; TERESO, M. J. A. Análise ergonômica do trabalho em unidades de beneficiamento de produtos agrícolas: exigências laborais dos postos de seleção. Ciência Rural, Santa Maria, v. 39, n. 5, p. 1552-1557, 2009. http://dx.doi. org/10.1590/S0103-84782009005000075.

BRASIL. Ministério da Agricultura, Pecuária e Abastecimento. Plano Agrícola e Pecuário. Brasília: MAPA, 2012.

BUCHHOLZ, B. et al. PATH: a work sampling-based approach to ergonomic job analysis for construction and other non-repetitive work. Applied Ergonomics, Guildford, v. 27, n. 3, p. 177-187, 1996. http://dx.doi. org/10.1016/0003-6870(95)00078-X. PMid:15677058.

CERF, M.; SAGORY, P. Agricultura e desenvolvimento agrícola. In: FALZON, P. (Org.). Ergonomia. São Paulo: Edgar Blucher, 2007. p. 535-544.

DINTEN, C. M.; ABRAHÃO, R. F.; OLIVEIRA, J. A. Work organization and technological resources in broiler production - an ergonomics approach. Scientia Agricola, Piracicaba, v. 63, n. 1, p. 46-54, 2006. http:// dx.doi.org/10.1590/S0103-90162006000100008.

FATHALLAH, F. A. Musculoskeletal disorders in labor-intensive agriculture. Applied Ergonomics, Guildford, v. 41, n. 6, p. 738-743, 2010. http://dx.doi. org/10.1016/j.apergo.2010.03.003. PMid:20398891.

GEMMA, S. F. B.; ABRAHÃO, R. F.; SZNELWAR, L. I. O trabalho no cultivo orgânico de frutas: uma abordagem ergonômica. Revista Brasileira de Saúde Ocupacional, São Paulo, v. 29, n. 109, p. 37-44, 2004. http://dx.doi.org/10.1590/S0303-76572004000100006.

GEMMA, S. F. B.; TERESO, M. J. A.; ABRAHÃO, R. F. Ergonomia e complexidade: o trabalho do gestor na agricultura orgânica na região de Campinas - SP. Ciência Rural, Santa Maria, v. 40, n. 2, p. 288-294, 2010. http://dx.doi.org/10.1590/S010384782010005000005 .

GONZAGA, M. C.; ABRAHÃO, R. F.; BRAUNBECK, O. A. O uso de luvas de proteção no corte manual da cana-de-açúcar. Revista Brasileira de Saúde Ocupacional, São Paulo, v. 30, n. 111, p. 35-40, 2005. 
GUÉRIN, F. et al. Compreendendo o trabalho para transformá-lo: a prática da ergonomia. São Paulo: Blücher, 2001.

GUIMARÃES, M. C. Só se eu arrumasse uma coluna de ferro pra aguentar mais... - contexto de produção agrícola, custo humano do trabalho e vivências de bem-estar e mal-estar entre trabalhadores rurais. 2007. 273 f. Tese (Doutorado em Psicologia)-Instituto de Psicologia, Universidade de Brasília, Brasília, 2007.

GUIMARÃES, M. C.; BRISOLA, M. V.; ALVES, R. A. Valores culturais, cultura brasileira e relações de trabalho no campo. In: ENCONTRO ANUAL DA ASSOCIAÇÃO NACIONAL DOS CURSOS DE GRADUAÇÃO EM ADMINISTRAÇÃO, 16. 2005. Belo Horizonte. Anais... Belo Horizonte: ANGRAD, 2005. p. 1669-1679.

INSTITUTO BRASILEIRO DE GEOGRAFIA E ESTATÍSTICA - IBGE. Estatística da produção agrícola de 2012. Brasília, DF: IBGE, 2012.

IIDA, I. Ergonomia, projeto e produção. 2. ed. São Paulo: Edgard Blücher, 2005.

INTERNATIONAL LABOUR ORGANIZATION ILO. Agriculture: a hazardous work. Genebra: ILO, 2009. Disponível em: <http://www.ilo.org/safework/ areasofwork/hazardous-work/lang--en/index.htm $>$. Acesso em: 15 jun. 2009.

KAGEYAMA, A.; BERGAMASCO, S. M. P. P.; OLIVEIRA, J. A. Uma classificação dos estabelecimentos agropecuários do Brasil a partir do censo de 2006. In: SCHNEIDER, S.; FERREIRA, B.; ALVES, F. (Org.). Aspectos multidimensionais da agricultura brasileira: diferentes visões do censo agropecuário de 2006. Brasília, DF: Ipea, 2013. cap. 1. p. 19-37.

MONTEDO, U. B.; SZNELWAR, L. I. Análise ergonômica do trabalho agrícola familiar na produção de leite. Produção, São Paulo, v. 18, n. 1, p. 142-154, 2008.

MORIN, E. Ciência com consciência. 7. ed. Rio de Janeiro: Bertrand Brasil, 2003.

ORGANISATION FOR ECONOMIC CO-OPERATION AND DEVELOPMENT - OECD. Oslo Manual: guidelines for collecting and interpreting innovation data. 3. ed. Paris: OECD, 2005.

PINZKE, S. Observational methods for analyzing working postures in agriculture. Journal of Agricultural Safety and Health, Harrisburg, v. 3, n. 3, p. 169-197, 1997. http://dx.doi.org/10.13031/2013.17753.

RIBEIRO, I. A. V.; TERESO, M. J. A.; ABRAHÃO, R. F. Análise ergonômica do trabalho em unidades de beneficiamento de tomates de mesa: movimentação manual de cargas. Ciência Rural, Santa Maria, v. 39, n. 4, p. 1073-1079, 2009. http://dx.doi.org/10.1590/ S0103-84782009005000037.

TERESO, M. J. A. et al. Work and technological innovation in organic agriculture. Work, Reading, v. 41, p. 4975-4978, 2012. Suplemento 1. PMid:22317490.

VEIGA, M. M. et al. A contaminação por agrotóxicos e os equipamentos de proteção individual (EPI). Revista Brasileira de Saúde Ocupacional, São Paulo, v. 32, n. 116, p. 57-68, 2007.

WISNER, A. Por dentro do trabalho: ergonomia, método \& técnica. São Paulo: Oboré, 1987. 